\title{
PENGARUH PERSEPSI PELAYANAN DAN FASILITAS RUANG TUNGGU TERHADAP KEPUASAN PELANGGAN DI BENGKEL PT. MITRA PINASTHIKA MUSTIKA (MPM) AUTO NISSAN \\ (Studi Kasus pada Bengkel MPM Auto Nissan Alam Sutera)
}

\author{
Oleh: \\ Suprapto \\ Program Studi Pendidikan Ekonomi, \\ Fakultas Ilmu Pendidikan dan Pengetahuan Sosial \\ Universitas Indraprasta PGRI \\ Email: \\ suprapto.tso@gmail.com
}

\begin{abstract}
ABSTRAK
Penelitian ini bertujuan Untuk mengetahui pengaruh persepsi pelayanan dan fasilitas ruang tunggu terhadap kepuasan pelanggan, di bengkel MPM Auto Nissan Alam Sutera Tangerang. Metode penelitian yang digunakan adalah metode survei. Sampel dilakukan terhadap 78 orang pelanggan yang diambil secara random. Analisis data meliputi analisis deskriptif, koefisien regresi, kofisien korelasi, dan koefisien determinasi. Uji statistik yang digunakan uji $\mathrm{F}$ dan uji $\mathrm{t}$ dengan bantuan SPSS 16. Penelitian ini dilaksanakan dari bulan Mei sampai dengan bulan Agustus 2015. Hasil penelitian menunjukan: 1) Persepsi pelayanan dan fasilitas ruang tunggu secara bersama-sama memberikan pengaruh terhadap kepuasan pelanggan dengan koefisien korelasi sebesar 0.739 dan koefisien determinasi sebesar 73.9 persen. Persamaan regresi yang terbentuk adalah $\hat{Y}=$ $1.988+0.266 \mathrm{X}_{1}+0.436 \mathrm{X}_{2}$ dengan signifikansi regresi pada uji $\mathrm{F}$ diperoleh $\mathrm{Fo}=$ 105.948 dan sig. $=0.000<0.05$. 2) Persepsi pelayanan memberikan pengaruh terhadap kepuasan pelanggan dengan koefisien regresi $=0.266$ dengan nilai to $=$ 5.848 dan nilai sig $=0,000<0,05$. Dengan sumbangan mutlaknya sebesar 35.8 persen. 3) Fasilitas ruang tunggu memberikan pengaruh positif dan signifikan terhadap kepuasan pelanggan dengan koefisien regresi $=0.436$ dengan nilai to $=$ 6.153 dan nilai sig $=0,000<0,05$. Dengan sumbangan mutlaknya sebesar 38.1 persen. Hasil penelitian dapat disimpulkan bahwa terdapat pengaruh yang signifikan baik secara bersama-sama maupun secara parsial persepsi pelayanan dan fasilitas ruang tunggu terhadap kepuasan pelanggan.
\end{abstract}

Kata Kunci: Persepsi Pelayanan, Fasilitas Ruang Tunggu dan Kepuasan Pelanggan 


\section{A. PENDAHULUAN}

Pemenuhan kebutuhan dan keinginan serta nilai kualitas jasa sangat ditentukan oleh kepuasan pelanggan. Pelayanan yang kurang memuaskan akan menyebabkan berkurangnya pelanggan atau bahkan hilang karena pelanggan berpindah ke jasa layanan lain. Hal ini merupakan tantangan besar bagi perusahaan dalam membangun citra perusahaan dan memberikan pelayanan yang memuaskan. Oleh karena itu, perusahaan perlu mengetahui perilaku pelanggan dalam membeli, menggunakan, dan mengevaluasi jasa dalam rangka pemenuhan kebutuhan dan kepuasan pelanggan.

Kualitas pelayanan merupakan titik sentral bagi perusahaan jasa karena akan mempengaruhi kepuasan pelanggan. Hal ini dimaksudkan agar seluruh barang yang ditawarkan mendapat tempat yang baik di mata masyarakat. Kepuasan pelanggan akan muncul apabila kualitas pelayanannya baik, dimana kualitas pelayanan yang baik mencakup lima dimensi kualitas pelayanan, yaitu : bukti fisik (tangible), keandalan (reability), daya tanggap (responsiveness), jaminan (assurance), empati (empathy).

Menurut Tjiptono (2001) pada dasarnya tujuan dari suatu bisnis adalah untuk menciptakan konsumen yang merasa puas. Terciptanya kepuasan konsumen dapat memberikan beberapa manfaat, di antaranya hubungan antara perusahaan dan konsumennya menjadi harmonis, memberikan dasar yang baik bagi terciptanya kepuasan konsumen dan pembelian ulang, baik melalui rekomendasi dari mulut ke mulut (word-of-mouth) atau promosi langsung yang menguntungkan bagi perusahaan dan mengarah pada semakin meningkatnya jumlah konsumen baik dengan melakukan upaya pemasaran yang ekspansif maupun secara intensif. Melihat dari sisi perusahaan selaku penyedia produk atau jasa yang dibutuhkan oleh konsumen, dalam rangka memperoleh kemajuan dalam usaha dan mempertahankan kelangsungan bisnis maka perlu bagi perusahaan untuk menjaga agar konsumen yang memanfaatkan produk atau jasanya memperoleh tingkat kepuasan yang tinggi.

Dalam memberikan pelayanan, setidaknya bengkel harus memenuhi 5 kriteria kualitas pelayanan yang sering disebut RATER sehingga dapat menciptakan pelanggan yang loyal, yaitu reabillity (kehandalan), assurance (jaminan), tangible (bukti fisik), empathy (kepedulian), dan responsiveness (cepat tanggap), (Tjiptono, 2006).

PT Mitra Pinasthika Mustika Auto merupakan perusahaan yang bergerak di bidang Jasa, meliputi jasa penjualan kendaraan baru, jasa Service dan perawatan mobil dan jasa penjualan Spare Part, yang merupakan Dealer resmi dari PT Nissan Motor Distributor Indonesia, yang merupakan distributor kendaraan merk Nissan di Indonesia. PT MPM Auto merupakan Dealer Nissan kedua setelah PT Indomobil Nissan, PT MPM Auto saat ini memiliki 8 Cabang yaitu : Cabang Alam Sutera, Cabang Tj Priok, Cabang Pluit, Cabang Tambun, Cabang Cilacap, Cabang Tanjung Pinang, Cabang Bengkulu dan Cabang Kenjeran

Salah satu cara menciptakan pelayanan yang berkualitas adalah bengkel dapat membedakan dirinya sendiri dengan cara konsisten menyampaikan mutu lebih tinggi ketimbang pesaingnya, pihak bengkel melakukan interaksi dengan 
pelanggan yang disertai umpan balik sebagai kontrol dan ukuran keberhasilan. pelanggan yang loyal adalah alat promosi yang efektif. Dengan adanya pelanggan yang loyal akan sangat membantu pihak bengkel, karena pelanggan yang loyal, merupakan alat promosi dari mulut kemulut yang efektif. pelanggan yang loyal akan membawa pelanggan lainnya untuk menikmati pelayanan produk perusahaan.

Berdasarkan hal-hal di atas, penulis tertarik untuk meneliti pengaruh persepsi pelayanan dan fasilitas ruang tunggu terhadap kepuasan pelanggan di bengkel MPM Auto Nissan.

\section{B. TINJAUAN PUSTAKA}

\section{Kepuasan Pelanggan}

Persaingan antar perusahaan yang semakin ketat, faktor kepuasan pelanggan menjadi perhatian yang serius. Kepuasan pelanggan merupakan aspek penting dalam rangka bertahan dalam persaingan bisnis. Kepuasan merupakan tingkat perasaan seseorang setelah membandingkan kinerja atau hasil yang dia rasakan dibandingkan dengan harapannya (Kotler, 2000).

Kepuasan atau tidak kepuasan pelanggan adalah tanggapan pelanggan terhadap evaluasi ketidaksesuaian yang dirasakan setelah dipakai. Jadi, kepuasan merupakan fungsi dari kesan kinerja dan harapan. Kepuasan pelanggan dipengaruhi oleh kualitas pelayanan jasa yang terdiri dari bukti fisik, keandalan, daya tanggap, jaminan dan empati. Jika kualitas pelayanan berada dibawah harapan, pelanggan tidak puas, jika pelayanan melebihi harapan, maka pelanggan akan merasa puas atau senang.

Selain itu, kepuasan yang dirasakan pelanggan sangat penting bagi setiap perusahaan. Menurut Tjiptono (2008), pentingnya kepuasan pelanggan dalam konteks perilaku konsumen, ketidakpuasan jauh lebih dalam dan maju ketimbang telaah konsep kepuasan. Ada tiga argumen yang mendasari pendapat ini :

Pertama, berbagai penelitian menunjukan bahwa konsumen cenderung diam bila puas namun akan menceritakan pengalaman buruk kepada 8 sampai 10 orang lain. Kedua, sebagaimana diungkapkan pakar manajemen Theodore Levitt konsumen tidak merasa atau menyadari bahwa ia puas sampai ia mengalami masalah tertentu, (Sunandar, 2010). Ketiga, pemahaman mengenai ketidakpuasan pelanggan berkembang melalui dua bidang riset utama, yaitu riset disonansi dan perilaku komplain.

Berdasarkan argumen di atas, maka kepuasan pelanggan menjadi suatu hal yang sangat penting untuk digali dan dipenuhi oleh perusahaan.Tetapi sangat sulit bagi perusahaan untuk memahami makna dari kepuasan pelanggan.

\section{Atribut - atribut Pembentuk Kepuasan Pelanggan}

Atribut - atribut pembentuk kepuasan pelanggan merupakan kesesuaian harapan berupa gabungan dari kemampuan suatu produk dari produsen yang diandalkan, sehingga suatu produk yang dihasilkan dapat sesuai dengan apa yang dijanjikan oleh produsen. (Hawkins dan Loney dalam skripsi Ismail, 2010). 
Sedangkan menurut Tjiptono (2002), atribut - atribut pembentuk kepuasan pelanggan yaitu :

1. Kemudahan dalam memperoleh produk atau jasa yang ditawarkan oleh produsen.

2. Kesediaan untuk merekomendasikanproduk kepada teman atau keluarganya.

\section{Metode Pengukuran Kepuasan Pelanggan}

Perusahaan perlu melakukan pemantauan dan pengukuran terhadap kepuasan pelanggan karena hal ini telah menjadi hal yang essensial bagi tiap perusahaan. Langkah tersebut dapat memberikan umpan balik dan masukan bagi keperluan pengembangan dan implementasi strategi peningkatan kepuasan pelanggan.

Menurut Kotler (1997) metode - metode yang dapat dipergunakan setiap perusahaan untuk memantau dan mengukur kepuasan pelanggan adalah sebagai berikut :

1. Sistem keluhan dan saran ( complain and suggestion system )

Organisasi yang berorientasi pelanggan akan membuat pelanggannya memberikan saran atau keluhan, misalnya dengan memberikan formulir bagi pelanggan untuk melaporkan kesukaan atau keluhan, penempatan kotak saran. Alur informasi ini memberikan banyak gagasan balik dan perusahaan dapat bergerak lebih cepat untuk menyelesaikan masalah.

2. Survei pelanggan ( customer surveys)

Kepuasan pelanggan dapat diukur melalui pelanggan atas persepsinya terhadap kepuasannya.

3. Pembeli bayangan ( ghost shopping )

Cara lain untuk mengukur kepuasan pelanggan adalah dengan menyuruh orang berpura - pura menjadi pembeli dan melaporkan titik - titik kuat maupun lemah yang mereka alami sewaktu membeli produk perusahaan.

4. Analisis Kehilangan Pelanggan ( Lost Customer Analysis )

Perusahaan sebaiknya menghubungi para pelanggan yang telah berhenti membeli atau yang telah pindah pemasok agar dapat memahami mengapa hal ini terjadi dan supaya dapat mengambil kebijakan perbaikan/penyempurnaan selanjutnya. Bukan hanya exit interview saja yang perlu, tetapi pemantauan customer loss rate juga penting, dimana peningkatan customer loss rate menunjukan kegagalan perusahaan dalam memuaskan pelanggannya.

\section{Hubungan Kualitas Jasa dengan Kepuasan Pelanggan}

Kualitas jasa dan kepuasan pelanggan merupakan hal yang penting bagi perusahaan jasa. Salah satu upaya untuk menciptakan, memperhatikan dan meningkatkan hubungan dengan pelanggan adalah dengan memberikan jasa yang berkualitas secara konsisten dan nilai yang lebih baik pada setiap kesempatan serta memberikan jasa yang lebih unggul dari pesaing. Peningkatan kualitas produk (jasa) sangat diperlukan dalam perusahaan untuk mencapai kepuasan pelanggan. Karena kepuasan pelanggan adalah fokus utama perusahaan agar dapat 
bertahan ditengah persaingan usaha yang sangat tinggi dan semakin canggihnya kualitas hidup.

Perusahaan yang bergerak dibidang jasa, sarana untuk meningkatkan kepuasan pelanggan adalah melalui kualitas pelayanan yang diberikan. Kualitas pelayanan secara umum dinyatakan sebagai persyaratan yang penting untuk mengembangkan dan menjaga hubungan yang memuaskan pelanggan. Kualitas pelayanan yang baik akan cenderung dapat memuaskan pelanggan.

Menurut Kurtz dan Clow (1998) dalam Laksana (2008) ada 3 faktor yang mempengaruhi harapan pelanggan, yaitu : faktor internal yang meliputi kebutuhan individu pelanggan dan pengalaman masa lalu, faktor eksternal yang meliputi faktor sosial dan pembicaraan di antara pelanggan dan yang terakhir faktor dari produksi layanan yang ditawarkan, yaitu meliputi masalah tarif pelayanan, promosi, dan komunikasi. Ketiga faktor tersebut akan membentuk harapan dari pelanggan, yang nantinya akan selalu dibandingkan dengan kualitas pelayanan yang dirasakan atau diterima oleh pelanggan. Jika harapan pelanggan sama dengan kenyataannya atau bahkan melebihi dari harapannya, maka pelanggan akan merasa puas.

\section{Kualitas Pelayanan}

Kualitas pelayanan (service quality) merupakan konsep yang abstrak dan sukar dipahami, karena kualitas pelayanan memiliki karakteristik tidak berwujud, bervariasi, tidak tahan lama, serta produksi dan konsumsi jasa terjadi secara bersamaan (Tjiptono, 2010)".

Kualitas pelayanan merupakan tingkat keunggulan yang diharapkan dan pengendalian atas tingkat keunggulan tersebut untuk memenuhi keinginan pelanggan. Ada dua faktor yang mempengaruhi kualitas pelayanan, yaitu pelayanan yang diharapkan (expected service) dan pelayanan yang diterima (perceived service). Kepuasan pelanggan dipengaruhi oleh kualitas pelayanan, dalam hal ini kualitas pelayanan terdiri dari bukti fisik, keandalan, daya tanggap, jaminan, dan empati.

Apabila jasa yang diterima (perceived service) sesuai dengan yang diharapkan, maka kualitas pelayanan dipersepsikan baik atau memuaskan. Jika pelayanan yang diterima melampaui harapan pelanggan, maka kualitas pelayanan dipersepsikan sebagai kualitas yang ideal. Sebaliknya jika kualitas pelayanan yang diterima lebih rendah dari yang diharapkan maka kualitas pelayanan dipersepsikan buruk atau tidak memuaskan.

Dengan demikian, baik tidaknya kualitas pelayanan dalam memuaskan pelanggan tergantung pada kemampuan penyedia jasa dalam memenuhi harapan pelanggannya secara konsisten.

Berdasarkan riset yang telah dilakukan, (Gronross dalam Ismail, 2010) mengemukakan enam kriteria kualitas pelayanan yang dipersepsikan baik, yakni sebagai berikut :

1. Profesionalism and skill. Pelanggan mendapati bahwa penyedia jasa, karyawan, sistem opeasional, dan sumber daya fisik, memiliki kekuatan fisik dan keterampilan yang dibutuhkan untuk memcahkan masalah mereka secara profesional (outcome-related criteria) 
2. Attitudes and Behaviour. Pelanggan merasa bahwa karyawan jasa (customer contact personel) menaruh perhatian besar pada mereka dan berusaha membantu memecahkan masalah mereka secara spontan dan ramah (processrelated criteria).

3. Accessibilty and flexibility. Pelanggan merasa bahwa penyedia jasa,lokasi, jam operasi, karyawan, dan sistem operasionalnya, dirancang dan dioperasikan sedemikian rupa sehingga pelanggan dapat mengakses jasa tersebut dengan mudah. Selain itu, juga dirancang dengan maksud agar dapat menyesuaikan permintaan dan keinginan pelanggan secara luwes (process-related criteria)

4. Realibility and Trustworthiness. Pelanggan merasa bahwa apapun yang terjadi atau lebih disepakati, mereka bisa mengandalkan penyedia jasa beserta karyawan dan sistemnya dalam memenuhi janji dan melakukan segala sesuatu dengan mengutamakan kepentingan pelanggan (processrelated criteria)

5. Recovery. Pelanggan menyadari bahwa bila terjadi kesalahan atau sesuatu yang tidak diharapkan dan tidak dapat diprediksi, maka penyedia jasa akan segera mengambil tindakan untuk mengendalikan situasi dan mencari solusi yang tepat (process- related criteria)

6. Reputation and Credibility. Pelanggan meyakini bahwa operasi dari penyedia jasa dapat dipercaya dan memberikan nilai/ tambahan yang sepadan dengan biaya yang dikeluarkan (image-related criteria).

\section{METODE PENELITIAN}

Penelitian dilaksanakan dalam bentuk penelitian lapangan/ survei sedang metode yang digunakan adalah diskriptif analistis. Metode tersebut digunakan untuk mengetahui pengaruh satu variabel bebas terhadap satu variabel terikat (bivariat) atau pengaruh lebih dari dua variabel terhadap satu variabel terikat (multivariat) berdasarkan analisis regresi sederhana dan regresi ganda. Adapun desain penelitian dapat digambarkan sebagai berikut:

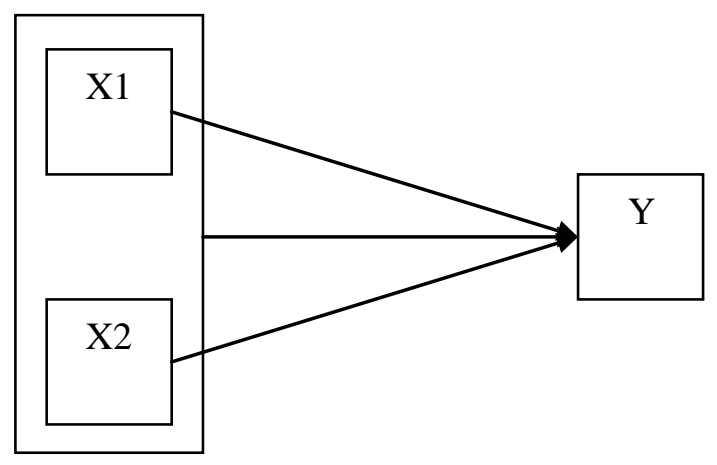

Gambar 1.

Konstelasi Pengaruh Variabel Bebas X1, X2 dan Variabel Terikat Y 
Keterangan :

$\mathrm{X}_{1} \quad=$ Pelayanan

$\mathrm{X}_{2} \quad=$ Fasilitas Ruang Tunggu

$\mathrm{Y}=$ Kepuasan Pelanggan

Pengambilan sampel dilakukan menggunakan teknik random sampling pada pelanggan di bengkel MPM Auto Nissan Alam Sutera Tangerang. Sampel dalam penelitian 78 pelanggan yang diperoleh dengan cara random.

\section{HASIL DAN PEMBAHASAN}

\section{Deskripsi Data}

Berdasarkan penghitungan menggunakan SPSS diperoleh hasil pengolahan data sebagai berikut:

Tabel 1.

Deskripsi Statistik Variabel Persepsi Pelayanan

Statistics

\begin{tabular}{|l|r|} 
Persensi.Pelawanan \\
\hline \multicolumn{1}{|c|}{ Valid } \\
Mean & 78 \\
Median & 0 \\
Mode & 26.15 \\
Std. Deviation & 24.00 \\
Skewness & 24 \\
Std. Error of Skewness & 2.955 \\
Kurtosis & .965 \\
Std. Error of Kurtosis & .272 \\
Range & -.429 \\
Minimum & .538 \\
Maximum & 11 \\
\hline
\end{tabular}

Dari tabel di atas dapat diketahui bahwa data persepsi pelayanan terletak pada rentangan nilai 21-32, dengan nilai rata-rata sebesar 26.15; nilai modus sebesar 24 median sebesar 24, nilai minimum 21, dan nilai maksimum 32 .

Dari analisis deskriptif di atas dapat disimpulkan bahwa persepsi pelayanan berada dalam kategori sedang, hal ini juga terlihat dari besar nilai modus dan rata-rata yang berada di sekitar median. 
Tabel 2.

Deskripsi Statistik Variabel Fasilitas Ruang Tunggu

Statistics

\begin{tabular}{|c|c|}
\hline $\begin{array}{ll}\text { N } & \text { Valid } \\
& \text { Missing }\end{array}$ & $\begin{array}{r}78 \\
0\end{array}$ \\
\hline Mean & 15.50 \\
\hline Median & 15.00 \\
\hline Mode & 15 \\
\hline Std. Deviation & 1.898 \\
\hline Skewness & 1.280 \\
\hline Std. Error of Skewness & .272 \\
\hline Kurtosis & 1.084 \\
\hline Std. Error of Kurtosis & .538 \\
\hline Range & 7 \\
\hline Minimum & 13 \\
\hline Maximum & 20 \\
\hline
\end{tabular}

Dari tabel di atas dapat diketahui bahwa data fasilitas ruang tunggu terletak pada rentangan nilai $13-20$, dengan nilai rata-rata sebesar 15.50 ; nilai modus sebesar 15 median sebesar 15, nilai minimum 13, dan nilai maksimum 20.

Dari analisis deskriptif di atas dapat disimpulkan bahwa fasilitas ruang tunggu berada dalam kategori sedang, hal ini juga terlihat dari besar nilai modus dan rata-rata yang berada di sekitar median.

Tabel 3.

\section{Deskripsi Statistik Variabel Kepuasan Pelanggan}

Statistics

\begin{tabular}{|c|c|}
\hline $\begin{array}{l}\text { Nalid } \\
\text { Missing }\end{array}$ & $\begin{array}{r}78 \\
0\end{array}$ \\
\hline Mean & 15.72 \\
\hline Median & 15.00 \\
\hline Mode & 15 \\
\hline Std. Deviation & 1.712 \\
\hline Skewness & 1.759 \\
\hline Std. Error of Skewness & .272 \\
\hline Kurtosis & 1.751 \\
\hline Std. Error of Kurtosis & .538 \\
\hline Range & 6 \\
\hline Minimum & 14 \\
\hline Maximum & 20 \\
\hline
\end{tabular}

Dari tabel di atas dapat diketahui bahwa data kepuasan pelanggan terletak pada rentangan nilai 14-20, dengan nilai rata-rata sebesar 15.72; nilai modus sebesar 15, median sebesar 15, nilai minimum 14, dan nilai maksimum 20. 
Dari analisis deskriptif di atas dapat disimpulkan bahwa ketiga variabel penelitian yaitu persepsi pelayanan, fasilitas ruang tunggu dan kepuasan pelanggan berada dalam kategori sedang, hal ini juga terlihat dari besar nilai modus dan rata-rata yang berada di sekitar median. Dari ketiga variabel penelitian ini menunjukkan bahwa variabel fasilitas ruang tunggu paling heterogen dengan koefisien variasi 12.25 persen, dibandingkan dengan variabel persepsi pelayanan yang mempunya koefisien variasi sebesar 11.30 persen dan variabel kepuasan pelanggan sebesar 10.90 persen.

\section{Pengujian Persyaratan Analisis}

\section{Uji Multikolinieritas}

Tabel 4.

Uji Multikolinieritas

\begin{tabular}{|ll|r|c|}
\hline \multirow{2}{*}{ Model } & \multicolumn{2}{|c|}{ Collinearity Statistics } \\
\cline { 2 - 4 } & Tolerance & VIF \\
\hline 1 & (Constant) & & \\
& Persepsi.Pelayanan & .565 & 1.771 \\
& Fasilitas.Ruang.Tunggu & .565 & 1.771 \\
\hline
\end{tabular}

Berdasarkan tabel 4 terlihat kedua variabel bebas yang digunakan memiliki nilai tolerance lebih kecil dari 0.10 dan nilai VIF lebih besar dari 10 dengan demikian dapat disimpulkan tidak terdapat masalah pada variabel yang digunakan. Sehingga analisis regresi dapat dipergunakan dalam penelitian ini.

\section{Uji Heterokedastisitas}

Untuk pengujian heteroskedastisitas peneliti menggunakan SPSS 16 sebagai alat bantu pengolahan data.

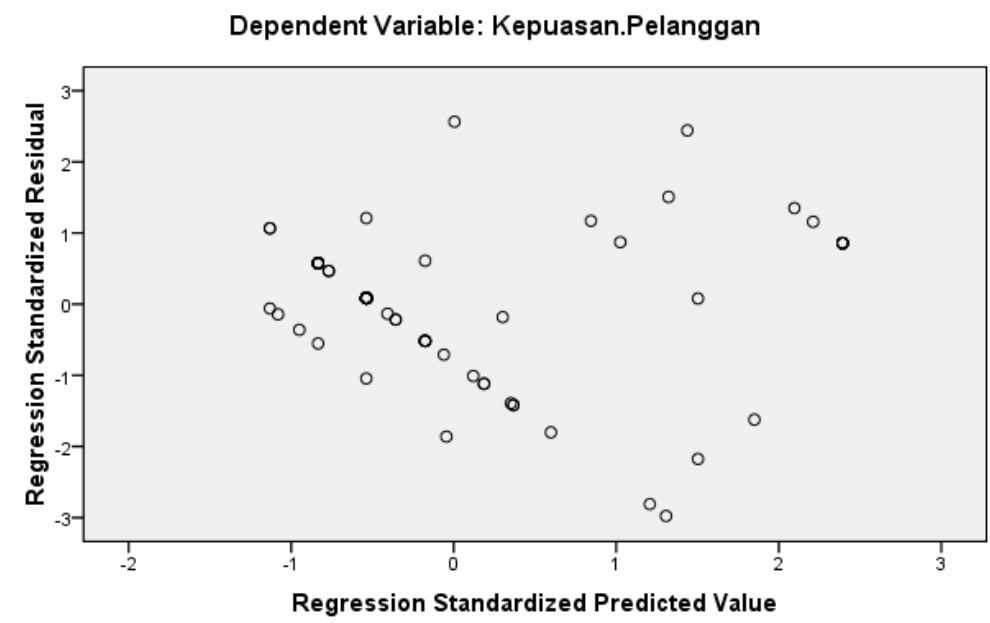

Gambar 2.

Diagram Pencar Z-Resid (Y) dan Z-Pred (X) 
Gambar 2 menunjukkan tidak ada pola yang sistematis dari nilai Z-Resid berapapun nilai Z-Pred. berdasarkan analisis ini menunjukkan bahwa data adalah homoskedastis. Sehingga aplikasi analisis regresi ganda menunjukkan bahwa tidak terdapat pola heteroskedastisitas dalam aplikasi ini, sehingga asumsi data homogen dapat dipenuhi.

\section{Pembahasan}

Hasil penelitian menunjukkan bahwa terdapat pengaruh persepsi pelayanan dan fasilitas ruang tunggu baik secara bersama-sama maupun secara parsial terhadap kepuasan pelanggan. Apabila dilihat dari variabel persepsi pelayanan nilai to $=5.848 \mathrm{dan}$ sig. $=0.000<0.05$ dan fasilitas ruang tunggu memiliki nilai to $=6.157 \mathrm{sig}$. $=0.000<0.05$, ini menunjukkan bahwa nilai to variabel fasilitas ruang tunggu lebih besar dibanding dengan nilai to variabel persepsi pelayanan.

\section{Pengujian Hipotesis Penelitian} berikut:

Hasil perhitungan dan pengujian hipotesis dapat dilihat pada tabel sebagai

Tabel 5.

Model Summary: R, dan R Squared (Koefisien Penentu)

\begin{tabular}{|l|c|r|r|r|}
\hline Mode & $\mathrm{R}$ & $\mathrm{R}$ Square & $\begin{array}{c}\text { Adjusted R } \\
\text { Square }\end{array}$ & $\begin{array}{c}\text { Std. Error of } \\
\text { the Estimate }\end{array}$ \\
\hline 1 & $.859^{\mathrm{a}}$ & .739 & .732 & .887 \\
\hline
\end{tabular}

a. Predictors: (Constant), Fasilitas.Ruang.Tunggu, Persepsi.Pelayanan

b. Dependent Variable: Kepuasan.Pelanggan

Tabel 6.

Analysis Of Variance Signifikansi Pengaruh Variabel Persepsi Pelayanan dan Fasilitas Ruang Tunggu Secara Bersama-Sama terhadap Kepuasan Pelanggan

ANOVA $^{\text {b }}$

\begin{tabular}{|ll|r|r|r|r|r|}
\hline Model & & \multicolumn{1}{c|}{$\begin{array}{c}\text { Sum of } \\
\text { Squares }\end{array}$} & df & Mean Square & F & Sig. \\
\hline 1 & Regression & 166.768 & 2 & 83.384 & 105.948 & $.000^{=}$ \\
& Residual & 59.027 & 75 & .787 & & \\
& Total & 225.795 & 77 & & & \\
\hline
\end{tabular}

a. Predictors: (Constant), Fasilitas.Ruang.Tunggu, Persepsi.Pelayanan

b. Dependent Variable: Kepuasan.Pelanggan 
Tabel 7.

Koefisien Regresi dan Uji Signifikansi Secara Parsial

\begin{tabular}{|c|c|c|c|c|c|c|}
\hline \multirow[b]{2}{*}{ Madel } & & \multicolumn{2}{|c|}{ Unstandardized Coefficients } & \multirow{2}{*}{$\begin{array}{c}\text { Standardized } \\
\text { Coefficients } \\
\text { Beta } \\
\end{array}$} & \multirow[b]{2}{*}{$\mathrm{t}$} & \multirow[b]{2}{*}{ Sig. } \\
\hline & & B & Std. Error & & & \\
\hline \multirow[t]{3}{*}{1} & (Constant) & 1.988 & .953 & & 2.086 & .040 \\
\hline & Persepsi.Pelayanan & .266 & .046 & .460 & 5.848 & .000 \\
\hline & Fasilitas.Ruang.Tunggu & .436 & .071 & .484 & 6.157 & .000 \\
\hline
\end{tabular}

a. Dependent Variable: Kepuasan.Pelanggan

1. Pengaruh persepsi pelayanan dan fasilitas ruang tunggu secara bersamasama terhadap kepuasan pelanggan

Hipotesis pengaruh secara bersama-sama ini adalah:

$\mathrm{H}_{0}: \beta_{\mathrm{y} 1}=\beta_{\mathrm{y} 2}=0$

$\mathrm{H}_{1}: \beta_{\mathrm{y} 1} \neq 0$ dan $\beta_{\mathrm{y} 2} \neq 0$;

Artinya:

H0 Tidak terdapat pengaruh persepsi pelayanan dan fasilitas ruang tunggu secara bersama-sama terhadap kepuasan pelanggan

H1 terdapat pengaruh persepsi pelayanan dan fasilitas ruang tunggu secara bersama-sama terhadap kepuasan pelanggan.

Berdasarkan pada tabel 4.6 menunjukkan bahwa nilai $\mathrm{Fo}=105.948$ dan sig. $=0.000<0.05$. hal ini menunjukkan bahwa Ho ditolak dan $\mathrm{H}_{1}$ diterima. Ini berarti hipotesis penelitian diterima. Artinya, terdapat pengaruh yang signifikan persepsi pelayanan dan fasilitas ruang tunggu secara bersamasama terhadap kepuasan pelanggan.

2. Pengaruh persepsi pelayanan terhadap kepuasan pelanggan

Hipotesis pengaruh partial pertama ini adalah:

$\mathrm{H}_{0}: \beta_{\mathrm{y} 1}=0$

$\mathrm{H}_{1}: \beta_{\mathrm{y} 1} \neq 0$;

Artinya:

H0 tidak terdapat pengaruh persepsi pelayanan terhadap kepuasan pelanggan

H1 terdapat pengaruh persepsi pelayanan terhadap kepuasan pelanggan

Berdasarkan tabel 4.7 didapatkan nilai to $=5.848$ dan sig. $=0.000<$ 0.05. hal ini menunjukkan bahwa Ho di tolak dan $\mathrm{H}_{1}$ diterima, ini berarti hipotesis penelitian diterima. Artinya, terdapat pengaruh persepsi pelayanan terhadap kepuasan pelanggan.

3. Pengaruh fasilitas ruang tunggu terhadap kepuasan pelanggan

Hipotesis pengaruh partial kedua ini adalah:

$\mathrm{H}_{0}: \beta_{\mathrm{y} 2}=0$

$\mathrm{H}_{1}: \beta_{\mathrm{y} 2} \neq 0$;

Artinya:

H0 tidak terdapat pengaruh fasilitas ruang tunggu terhadap kepuasan pelanggan

H1 terdapat pengaruh fasilitas ruang tunggu terhadap kepuasan pelanggan 
Berdasarkan tabel 4.7 didapatkan nilai to $=6.157$ dan sig. $=0.000<0.05$. Hal ini menunjukkan bahwa Ho di tolak dan $\mathrm{H}_{1}$ diterima, ini berarti hipotesis penelitian diterima. Artinya, terdapat pengaruh fasilitas ruang tunggu terhadap kepuasan pelanggan.

\section{E. SIMPULAN}

Dari hasil penelitian yang telah dibahas pada bab sebelumnya, maka penulis dapat menyimpulkan hasil penelitian sebagai berikut :

1. Terdapat pengaruh yang signifikan persepsi pelayanan dan persepsi fasilitas ruang tunggu secara bersama sama terhadap kepuasan pelanggan. Hal ini dibuktikan dengan nilai Fo $=105,948$ dan sig $=0.000<0,05$.

2. Terdapat pengaruh yang signifikan persepsi pelayanan terhadap kepuasan pelanggan. Hal ini dapat dibuktikan dengan nilai to $=5,848$ dan sig $=0,000<$ 0,05 .

3. Terdapat pengaruh yang signifikan persepsi fasilitas ruang tunggu terhadap kepuasan pelanggan. Hal ini dapat dibuktikan dengan nilai to $=6,157$ dan sig $=0,000<0,05$. 


\section{DAFTAR PUSTAKA}

Ismail, Yulianto. (2010). Analisis Pengaruh Kualitas Pelayanan Terhadap Kepuasan Pelanggan Pada PT FIF Cabang Semarang. Skripsi. Fakultas Ekonomi Universitas Diponegoro.

Kotler, Philip. (2000). Marketing Management: Edisi Milenium. International Edition. New Jersey: Prentice Hall International, Inc.

Philip. (1997). Manajemen Pemasaran. Jakarta: Prenhallindo

Laksana, Fajar. (2008). Pemasaran Jasa (Edisi 1). Yogyakarta: Graha Ilmu

Sunandar, D. (2010). Analisis Kepuasan Pelanggan dengan Metode Servqual yang Mempengaruhi Intensitas Pembelian Pelanggan pada Biro Perjalanan ABC. Skripsi. Fakultas Ekonomi Universitas Indonesia.

Tjiptono, Fandy. (2001). Prinsip-prinsip Total Quality Service (TQS). Yogyakarta: Penerbit Andi.

Fandy. (2002). Prinsip-Prinsip Total Quality Service. Yogyakarta: Penerbit Andi.

, Fandy. 2006. Manajemen Pelayanan Jasa. Yogyakarta: Penerbit Andi.

, Fandy. 2008. Service Management Mewujudkan Layanan Prima. Edisi II Yogyakarta: C.V ANDI OFFSET. 